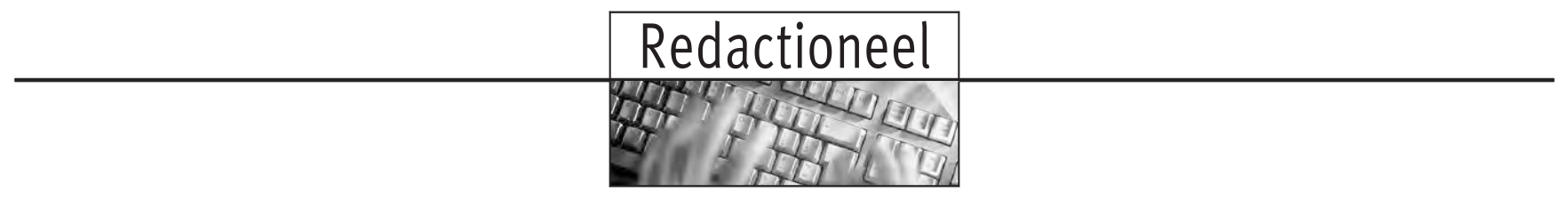

\title{
Het digitale dossier Jeugdgezondheidszorg: schaap met vijf poten?
}

De Jeugdgezondheidszorg (JGZ) gebruikt sinds enkele jaren een digitaal kinddossier om gegevens over de preventieve gezondheidsonderzoeken (PGO's) in op te slaan. De JGZ-instellingen hebben een wettelijke plicht om een digitaal dossier van alle jeugdigen van 0 tot 19 jaar bij te houden. Het digitale dossier vervangt het reeds 100 jaar gebruikte papieren dossier JGZ. In het dossier leggen de professionals de bevindingen van de PGO's vast, welke gezondheidsproblemen zij bij het kind vaststellen en welke vervolgstappen worden ondernomen. Naast de mogelijkheid van individuele verslaglegging, worden ongekende mogelijkheden voorzien om met de digitale gegevens van ongeveer 200.000 jeugdigen per jaargroep, die op 17 contactmomenten worden gevolgd, informatie te genereren voor onderzoek en beleid. Het digitale registratiesysteem lijkt een schaap met vijf poten te zijn geworden. Maar in hoeverre zijn beide doeleinden te verenigen? Kan met één systeem zowel het volgen van zorg, als het genereren van databestanden voor beleid en onderzoek worden gerealiseerd?

Het systematisch en eenduidig verzamelen van gegevens in een digitaal dossier heeft veel voordelen. De JGZ maakt gebruik van een landelijke basisdataset (BDS). Hierdoor wordt minder aan het toeval of de voorkeur van de professional overgelaten, wat deze over een kind wel of niet registreert. Door gebruik van het digitale dossier en de BDS zijn JGZ-professionals beter in staat om de ontwikkeling en gezondheid van kinderen te kunnen volgen en adequate zorg te leveren. Een digitaal dossier zorgt verder voor een makkelijker overdracht tussen de JGZinstellingen, waardoor dossiers van kinderen beter en sneller beschikbaar en toegankelijk zijn. Maar het grote aantal variabelen dat moet worden geregistreerd en de rigiditeit van de antwoordcategorieën van de BDS roept bij professionals ook weerstand op. Daardoor laten professionals soms een vrij tekstveld prevaleren om de zorg over een kind of gezin weer te geven. Dit ondermijnt helaas de mogelijkheid om gestandaardiseerde gegevens uit het dossier te halen voor beleid en onderzoek.

Voor JGZ-instellingen en beleidsmakers bieden de digitaal gegenereerde gegevens mogelijkheden voor sturing op de zorg. Vergelijkingen tussen uniform verkregen gegevens kunnen een belangrijke bijdrage leveren aan kwaliteitsverbetering. Veel JGZ-instellingen stappen over naar een flexibelere omgang met het basistakenpakket JGZ en geven ruimte aan een variabele invulling van de gezondheidszorgonderzoeken. Ook is er ruimte voor het uitvoeren van gezondheidsonderzoeken door andere disciplines dan de jeugdarts. Met de analyse van de gegevens uit het digitale dossier kan de JGZ-instelling verantwoorden welke zorg is geleverd en hoe deze verbeterd kan worden.

De registratie van kindgegevens levert verder voor de gemeentelijke overheid, die de JGZ financiert, bruikbare beleidsinformatie op. Dit is zeker van belang gezien de transitie en transformatie van de jeugdzorg. Verwacht kan worden dat de vraag naar gebruik van registratiegegevens voor beleidsanalyses in de toekomst zal stijgen. De lokale overheid wordt per 1 januari 2015 verantwoordelijk voor alle zorg voor jeugd in gemeenten. Om goede integrale zorg te leveren is het nuttig om inzicht te krijgen in geregistreerde gegevens uit zowel het gezondheidszorgdomein als het sociale domein, waaronder jeugdzorg en jeugd geestelijke gezondheidszorg. De JGZ voelt de spanning tussen verantwoording afleggen en de vraag wat het bestuur met de informatie uit registratiedata gaat doen. Een meer holistisch en integrale benadering van de zorg in de toekomst, samen met andere jeugdinstellingen, is een uitdaging. Het vraagt om een goede planning van toegang en uitwisseling van data. Het vraagt om een goede afweging van alle belangen van zorgaanbieders en beleid.

Een digitaal registratiesysteem biedt tot slot goede mogelijkheden voor het doen van wetenschappelijk onderzoek. Er is nog nauwelijks gebruik gemaakt van JGZdata voor onderzoek, omdat de meeste instellingen nog maar kort ervaring hebben met het opslaan van de gegevens uit de basisdataset in een gestandaardiseerd digitaal dossier. De auteurs van dit redactioneel zijn betrokken geweest bij wetenschappelijk onderzoek naar triage in de JGZ, waarbij voor het eerst ervaring is opgedaan met het gebruik van deze rijke bron van digitale gegevens van vier JGZ-instellingen. Triage is een vorm van flexibilisering van de uitvoering van de PGO's in de JGZ door middel van taakdelegatie. Bij triage worden niet alle kinderen door een jeugdarts of -verpleegkundige gezien. Een doktersassistente voert volgens een vast protocol een gezondheidsonderzoek uit bij alle kinderen die in aanmerking komen voor een wettelijk verplicht contactmoment. De kinderen bij wie een risico op een gezondheidsprobleem wordt vastgesteld, gebaseerd op de informatie van de ouders, de school en het gezondheidsonderzoek, worden verwezen naar een vervolgonderzoek door een arts of verpleegkundige. In het onderzoek naar de effecten van triage is deze methode vergeleken met de traditionele uitvoering van de onderzoeken door jeugdartsen of -verpleegkundigen. Met behulp van de registratiegegevens van de vier JGZ-instellingen zijn opkomstpercen- 
tages, incidentiecijfers van een aantal gezondheidsproblemen, verwijzingen naar extra zorg en kosten van de twee methoden vergeleken.

Zoals kan worden verwacht van een nieuw digitaal registratiesysteem, stuitte het onderzoek naar triage op verschillende problemen. Deze betreffen de compleetheid, bruikbaarheid en validiteit van de data. De aangeleverde bestanden van de JGZ-instellingen bleken incompleet wat tot missende waarden heeft geleid. De bruikbaarheid van de data bleek door beperkingen van de datasystemen te worden gehinderd. Alhoewel het registreren van cliëntgegevens verplicht is voor de JGZ, is het aan de instellingen zelf overgelaten welke techniek de instellingen voor dit dossier gebruiken. De instellingen die deelnamen aan het onderzoek maakten gebruik van twee verschillende systemen geleverd door verschillende providers. Het bleek dat instellingen moeite hadden om de juiste gegevens uit het systeem te halen. Oplossingen waren nodig, zoals het handmatig vergelijken van datavelden en het voeren van een schaduwregistratie via een ander programma. Om de validiteit en betrouwbaarheid te verhogen werd door de JGZ veel tijd gestoken in protocollering en instructie van medewerkers ten behoeve van de invoer van data.

Niet alle belanghebbenden zien de voordelen van een systeem waarmee met één druk op de knop zorggegevens beschikbaar komen. De opslag van gegevens in een digitaal dossier roept reacties op van burgers en politiek. Is de opslag voldoende beveiligd, wie kan er bij de gegevens en waarvoor worden de gegevens gebruikt? In de Tweede Kamer zijn vragen gesteld over de gegevensverzameling door de JGZ. Ook ouders volgen het opslaan van gegevens in een cliëntdossier kritisch, zoals het registreren van gevoelige gegevens, die ouders invullen in de vragenlijst vooraf aan het PGO. In haar column in de Volkskrant was Sheila Sitalsing kritisch over de ingrijpende vragen die zij moest invullen over het beroep van de ouders of over hun psychische klachten. ${ }^{1}$ Ze vroeg zich af of de JGZ de beveiliging van de computerdata voldoende op orde had.

De voordelen van digitale registratie van cliëntgegevens zijn evident: onderbouwing van advies en verwijzing door de JGZ-professional, inzicht in geleverde zorg voor instelling en overheid, en de mogelijkheid van wetenschappelijk onderzoek. Maar de extra registratiedruk, de inbreuk in privacy, vragen over veiligheid en de proble- men met de techniek, vormen een bedreiging voor een goed gebruik van JGZ-data. Het zichtbaar maken dat het gebruik van in de digitale dossiers opgeslagen data iets oplevert, blijkend uit bijvoorbeeld onderzoeksresultaten, vergroot wellicht de acceptatie en motivatie om gezondheidsgegevens goed te registreren. JGZ-instellingen en -professionals moeten zich er beter van bewust worden dat gezondheidsbewaking door middel van goede gegevens over de jeugdigen, een belangrijke kerntaak is van publieke zorg. Een even belangrijke taak als het volgen van de gezondheid en ontwikkeling van de aan hun toevertrouwde doelgroep jeugdigen. Voor wetenschappelijk onderzoek is het nodig dat JGZ-instellingen werken aan de volledigheid en bruikbaarheid van de data in het digitale cliëntdossier. Ook moet aan ouders beter worden uitgelegd waarom en hoe gegevens worden vastgelegd en hoe ouders en jongeren inzicht kunnen krijgen in hun dossier. De burger moet goed worden geïnformeerd en betrokken bij het opstellen van gedragscodes rond privacy en ethiek.

Burgers, professionals, zorgaanbieders, beleid en politiek dragen samen verantwoordelijkheid voor het realiseren en continueren van digitale gegevensverzameling door de JGZ. Een kritische houding over het verzamelen en gebruiken van data houdt de partijen daarbij scherp. Met duidelijke communicatie over het doel van registratie, investering in de techniek van digitale dataregistratie en -verwerking, en het laten zien van de uitkomsten van het gebruik van anonieme gegevens voor beleid en onderzoek, is er toekomst voor het nog prille digitale cliëntdossier in de JGZ.

Janine Bezem, Veiligheids- en Gezondheidsregio Gelderland Midden, Arnhem

Paul Kocken, TNO Child Health, Leiden

\section{LITERATUUR}

1. Sitalsing $S$. Jeugdgezondheidszorg, wij vermoeden dat U lijdt aan de illusie van controle. De Volkskrant, 14 april 2014.

\section{CORRESPONDENTIEADRES}

Paul Kocken, TNO, postbus 3005, 2301 PA Leiden, e-mail: paul.kocken@tno.nl 